\title{
Produção e valor nutritivo da forragem, e desempenho de bovinos Nelore em pastagem de capim-Tanzânia adubado com nitrogênio ou consorciado com estilosantes Campo Grande
}

\author{
Production and nutritive value of forage, and performance of \\ Nellore cattle in Tanzania grass pasture fertilized with nitrogen or \\ intercropped with Sthylosantes Campo Grande
}

\author{
Alyson Andrade Pinheiro ${ }^{1 *}$; Ulysses Cecato ${ }^{2}$; Túlio Otávio Jardim D’almeida Lins ${ }^{2}$; \\ Tatiane Beloni' ${ }^{2}$, Vanessa Cristina Piotto ${ }^{2}$; Ossival Lolato Ribeiro ${ }^{3}$
}

\section{Resumo}

\begin{abstract}
Objetivou-se avaliar o desempenho de bovinos Nelore em pastagem de capim-Tanzânia (Panicum maximum Jacq. cv. Tanzânia-1) adubado com nitrogênio ou consorciado com estilosantes Campo Grande (Stylosanthes ssp). Utilizou-se um delineamento experimental em blocos ao acaso com parcelas subdivididas, com três repetições e quatro tratamentos: Tanzânia + Estilosantes; Tanzânia $+75 \mathrm{~kg}$ de $\mathrm{N} \mathrm{ha}^{-1}$ ano $^{-1}$; Tanzânia $+150 \mathrm{~kg}$ de $\mathrm{N} \mathrm{ha}^{-1}$ ano $^{-1}$; Tanzânia $+225 \mathrm{~kg} \mathrm{de} \mathrm{N} \mathrm{ha-1}^{-1}$ ano $^{-1}$. Nas subparcelas foram avaliadas as estações. O maior ganho médio diário (GMD) durante o outono foi observado nos tratamentos em consórcio e $75 \mathrm{~kg}$ de $\mathrm{N} \mathrm{ha}^{-1}$ ano $^{-1}$. O GMD observado nos tratamentos com 150 e $225 \mathrm{~kg}$ de $\mathrm{N} \mathrm{ha}^{-1}$ ano $^{-1}$ foram superiores aos demais na primavera e verão. A taxa de lotação (TL) foi semelhante entre as estações avaliadas. Foi observada maior TL quando foram utilizadas as maiores doses de adubação nitrogenada. $\mathrm{O}$ ganho de peso vivo por área foi superior na primavera e no verão quando comparado ao outono. A inclusão de leguminosas no sistema pecuário diminui a dependência do uso excessivo de fertilizantes nitrogenados e contribui no desempenho animal.

Palavras-chave: Forragicultura, ganho médio diário, leguminosa, massa de forragem, taxa de lotação
\end{abstract}

\begin{abstract}
The objective was to evaluate of Nelore performance on pasture of Tanzania (Panicum maximum Jacq. cv. Tanzania-1) fertilized with nitrogen or mixed with Stylosanthes Campo Grande (Stylosanthes spp). It was used a randomized complete blocks with split plots design and three replicates of four treatments: Stylosanthes + Tanzania; Tanzania $+75 \mathrm{~kg} \mathrm{de} \mathrm{N} \mathrm{ha}^{-1}$ ano $^{-1}$; Tanzania $+150 \mathrm{~kg} \mathrm{de} \mathrm{N} \mathrm{ha-1}$ ano $^{-1}$; Tanzania + $225 \mathrm{~kg} \mathrm{de} \mathrm{N} \mathrm{ha}^{-1}$ ano $^{-1}$. Plots were assessed by stations. The highest average daily gain (ADG) during the fall was observed in treatment in the consortium and $75 \mathrm{~kg} \mathrm{de} \mathrm{N} \mathrm{ha}^{-1} \mathrm{ano}^{-1}$. The ADG in the treatments of 150 and $225 \mathrm{~kg}$ de $\mathrm{N} \mathrm{ha}^{-1}$ ano $^{-1}$ were superior to others in spring and summer. Stocking rate (SR) was similar between the stations studied. The value of SR was higher when it was used the highest dose of nitrogen fertilizer. The weight gain per area was higher in the spring and summer compared to autumn. The inclusion of legumes in livestock system reduces the dependence of the overuse of nitrogen fertilizers.
\end{abstract}

Key words: Forage, average daily gain, legume, forage availability, stocking rate

\footnotetext{
${ }^{1}$ Pesquisador, Agência Goiana de Assistência Técnica, Extensão Rural e Pesquisa Agropecuária, Setor Leste Universitário Goiânia, GO. E-mail: jagualyson@bol.com.br

${ }^{2}$ Profs. e Discentes, Universidade Estadual de Maringá, UEM, Maringá, PR. E-mail: ucecato@yahoo.com.br; tuliootavio@ hotmail.com; tati.zoo@hotmail.com; vanepiotto@hotmail.com

${ }^{3}$ Prof., Universidade Federal da Bahia, Salvador, BA. E-mail: ossribeiro@yahoo.com.br

* Autor para correspondência
} 


\section{Introdução}

Em virtude das características climáticas e extensão territorial que são favoráveis à pecuária de corte, o Brasil possui o maior rebanho comercial bovino do mundo, com aproximadamente 193,4 milhões de animais (ANUALPEC, 2013), e nos últimos anos vem se firmando como o maior exportador de carne (GARCIA et al., 2011).

No Brasil, as pastagens constituem o principal e mais econômico componente da dieta de bovinos e, como tal, representam a base de sustentação da pecuária brasileira. De acordo com Martha Júnior e Corsi (2001), quase $90 \%$ da carne bovina produzida no Brasil é produzida exclusivamente em pastagens. Sendo assim, a produção de bovinos criados exclusivamente em pastagens, quando manejadas e utilizadas adequadamente, é uma alternativa viável para que o sistema de produção animal seja rentável economicamente.

O desempenho animal no pasto é altamente correlacionado com o consumo de forragem, uma vez que esta é a principal fonte de nutrientes para o animal. O conhecimento sobre a forragem consumida pelo animal em pastejo é de fundamental importância, principalmente em países tropicais, em que a pecuária tem como base as pastagens, e desse modo, espera-se que a quantidade de forragem consumida aliada a sua qualidade, atenda totalmente ou em grande parte as exigências de mantença, crescimento e produção do animal (PARIS et al., 2009).

A adubação nitrogenada é uma prática importante para o sucesso do manejo de pastagens com gramíneas tropicais. Por outro lado, a entrada de quantidades elevadas de fontes nitrogenadas, principalmente como adubos químicos, pode representar também fonte de degradação da qualidade ambiental, afetando a qualidade de águas subterrâneas (PRIMAVESI et al., 2001). Nesse sentido, a introdução de leguminosas em pastagens tem sido usada para suprir ou minimizar a deficiência de $\mathrm{N}$ desses ecossistemas, aumentando a capacidade de suporte, prolongando a produtividade e minimizando os possíveis danos ambientais.
A consorciação de leguminosas e gramíneas perenes em condições tropicais pode resultar em melhorias tanto do pasto como da produção animal, por seu efeito indireto sobre a biodiversidade do ecossistema de pastagens ou pelo efeito direto na dieta do animal (PIZARRO, 2001; PACIULLO et al., 2003). O consórcio incrementa a produtividade animal, por meio da manutenção do nível adequado de proteína bruta (PB) na dieta, seja pelo efeito direto da ingestão de leguminosas ou pelo efeito indireto do acréscimo no conteúdo de nitrogênio na pastagem, pela capacidade da leguminosa de fixar o $\mathrm{N}$ atmosférico e contribuir para o aumento da produção de forragem (ANDRADE et al., 2004).

Objetivou-se avaliar a produção e o valor nutritivo da forragem, bem como o desempenho de bovinos Nelore em pastagem de capim-Tanzânia (Panicum maximum Jacq. cv. Tanzânia-1) adubado com nitrogênio ou consorciado com estilosantes Campo Grande (Stylosanthes ssp).

\section{Material e Métodos}

O experimento foi conduzido na estância JAE, município de Santo Inácio-PR, região noroeste do Paraná. A localização geográfica é $23^{\circ} 25^{\prime}$ 'S de latitude e $51^{\circ} 57^{\prime} \mathrm{O}$ de longitude e possui altitude média de 410 metros. O tipo climático predominante na região é o $\mathrm{Cfa}$ - subtropical úmido mesotérmico (KÖPPEN), caracterizado pela predominância de verões quentes, baixa frequência de geadas severas e tendência de concentração das chuvas no período do verão, com temperatura média anual de $22,1^{\circ} \mathrm{C}$ e precipitação anual de $1200 \mathrm{~mm}$. O período experimental foi agosto de 2009 a maio de 2010 .

Os dados climáticos referentes à precipitação $(\mathrm{mm})$, umidade relativa do ar (\%), temperatura mínima, média e máxima $\left({ }^{\circ} \mathrm{C}\right)$, correspondentes ao período experimental podem ser visualizados na Figura 1.

O solo da região é o Latossolo Vermelho Escuro Distrófico de textura arenosa (EMBRAPA, 1999). A composição química do solo no início do período experimental pode ser visualizada na Tabela 1 . 
Figura 1. Dados climáticos observados durante o período experimental.

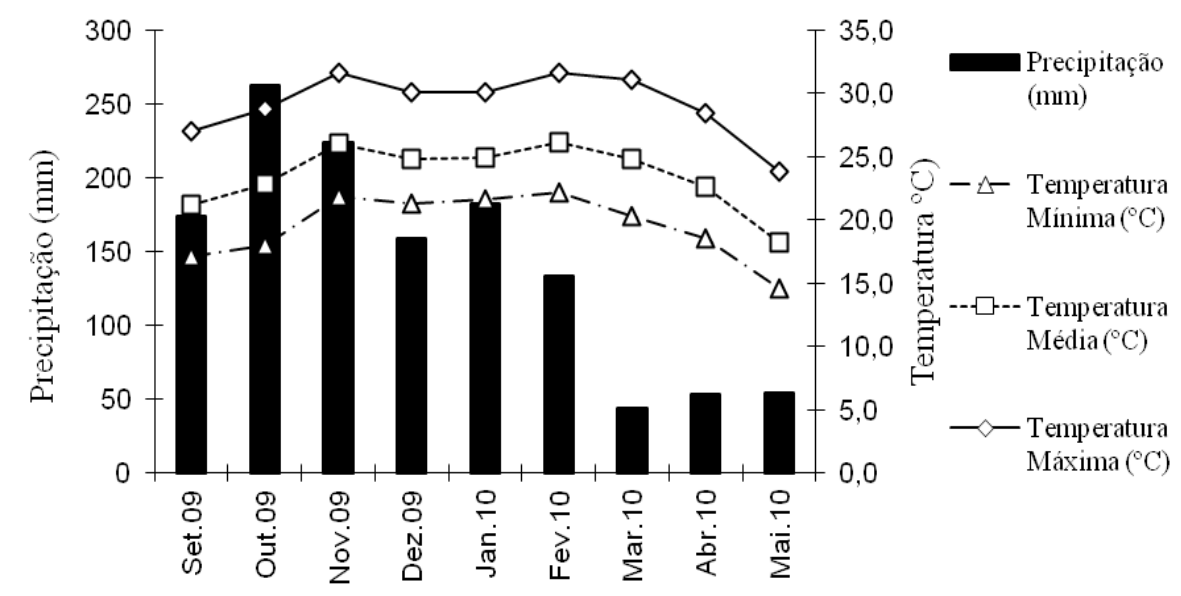

Fonte: Precipitação: Estância JAE; Temperatura: IAPAR - Paranavaí-PR.

Tabela 1. Composição química do solo da área no início do período experimental ( $0-20 \mathrm{~cm}$ de profundidade).

\begin{tabular}{|c|c|c|c|c|c|c|c|c|c|c|c|c|}
\hline \multirow{2}{*}{$\begin{array}{l}\text { TRATA- } \\
\text { MENTO }\end{array}$} & \multirow{2}{*}{\multicolumn{2}{|c|}{$\begin{array}{c}\mathrm{pH} \\
\mathrm{CaCl}_{2} \mathrm{H}_{2} \mathrm{O}\end{array}$}} & $\mathrm{Al}^{3+}$ & $\mathrm{H}^{+}+\mathrm{Al}^{3+}$ & $\mathrm{Ca}^{2+}$ & $\mathrm{Mg}^{2+}$ & $\mathrm{K}^{+}$ & SB & CTC & \multirow{2}{*}{$\begin{array}{c}\mathrm{P} \\
\mathrm{mg} \mathrm{dm}^{-3}\end{array}$} & \multirow{2}{*}{$\begin{array}{c}\mathrm{C} \\
\mathrm{g} \mathrm{dm}^{-3}\end{array}$} & \multirow[t]{2}{*}{$\mathrm{V} \%$} \\
\hline & & & \multicolumn{7}{|c|}{ 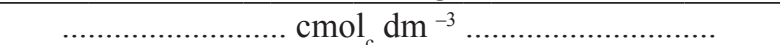 } & & & \\
\hline $\mathrm{Tz}+\mathrm{Est}^{1}$. & 5,40 & 6,33 & 0,00 & 2,25 & 1,18 & 0,54 & 0,12 & 1,59 & 3,95 & 8,45 & 6,10 & 40,14 \\
\hline 75 kg.N.ha & 5,20 & 6,20 & 0,00 & 2,30 & 1,03 & 0,40 & 0,11 & 1,54 & 3,84 & 4,77 & 6,65 & 40,00 \\
\hline 150 kg.N.ha & 5,43 & 6,40 & 0,00 & 2,14 & 1,15 & 0,45 & 0,09 & 1,69 & 3,83 & 7,07 & 5,29 & 41,52 \\
\hline 225 kg.N.ha & 5,40 & 6,37 & 0,00 & 2,19 & 1,05 & 0,46 & 0,11 & 1,62 & 3,81 & 8,53 & 6,40 & 42,38 \\
\hline
\end{tabular}

${ }^{1}$ Tanzânia + Estilosantes.

Fonte: Laboratório do Departamento de Agronomia da UEM.

A área experimental utilizada foi estabelecida em fevereiro de 2008 com capim-Tanzânia (Panicum maximun Jacq. cv. Tanzânia) na forma de monocultura e em consórcio com a leguminosa Estilosantes Campo Grande (80\% Stylosanthes capitata $+20 \%$ Stylosanthes macrocephala) e desde então vem sendo utilizada com os mesmos tratamentos. A área total da pastagem foi de 12 ha, dividida em três blocos e esses, por sua vez, subdivididos em quatro piquetes (unidades experimentais), perfazendo um total de 12 piquetes de um hectare. Cada unidade experimental possuía bebedouro com boia automática e cocho para sal mineral.

Utilizou-se um delineamento experimental em blocos ao acaso com parcelas subdivididas, com três repetições e tendo como tratamentos nas parcelas:
Tanzânia + Estilosantes; Tanzânia +75 kg N ha1; Tanzânia + 150 kg N ha ${ }^{-1}$; Tanzânia +225 kg N $\mathrm{ha}^{-1}$. Nas subparcelas foram avaliados os períodos, considerando-se como primavera (3 de outubro de 2009 a 19 de dezembro de 2009), verão (20 de dezembro de 2009 a 13 de março de 2010), outono (14 de março de 2010 a 8 de maio de 2010).

Antes do início do experimento (setembro de 2009), com base na análise do solo apresentada na Tabela 1, realizou-se a calagem do solo (calcário dolomítico), a fim de elevar a saturação por bases para 70\%, segundo WERNER et al. (1996). A adubação fosfatada foi realizada em uma única aplicação, 20 de setembro de 2009, sendo a fonte de fósforo utilizada o superfosfato simples $(60 \mathrm{~kg}$ $\left.\mathrm{P}_{2} \mathrm{O}_{5} \mathrm{ha}^{-1}\right)$. As adubações nitrogenadas $(75,150 \mathrm{e}$ $\left.225 \mathrm{~kg} \cdot \mathrm{ha}^{-1}\right)$ e potássicas $\left(60 \mathrm{~kg} \mathrm{~K} \mathrm{O} \mathrm{ha}^{-1}\right)$ foram 
realizadas a lanço, em três aplicações: 26 de outubro de 2009, 8 de janeiro de 2010 e 24 de março de 2010. Foram utilizados ureia e nitrato de amônio como fonte de nitrogênio e cloreto de potássio como fonte de potássio. O pasto foi manejado pelo método de lotação contínua com taxa de lotação variável, mantendo-se a altura do pasto entre 45 e $50 \mathrm{~cm}$. A altura média do pasto foi medida semanalmente, utilizando-se uma régua $(100 \mathrm{~cm})$, avaliando 50 pontos por piquete (Figura 2). Para a manutenção da altura e manejo do pasto foram utilizados novilhos da raça Nelore com peso vivo médio inicial de $230 \mathrm{~kg}$ (animais testes). Cada piquete possuía três animais testes e animais reguladores que eram colocados ou retirados dos piquetes em função da altura da pastagem, conforme o método "put and take" (MOTT; LUCAS, 1952). Uma área adjacente à experimental, com a mesma gramínea, foi disponibilizada para manutenção dos animais reguladores.

Figura 2. Altura média do pasto durante o período experimental.

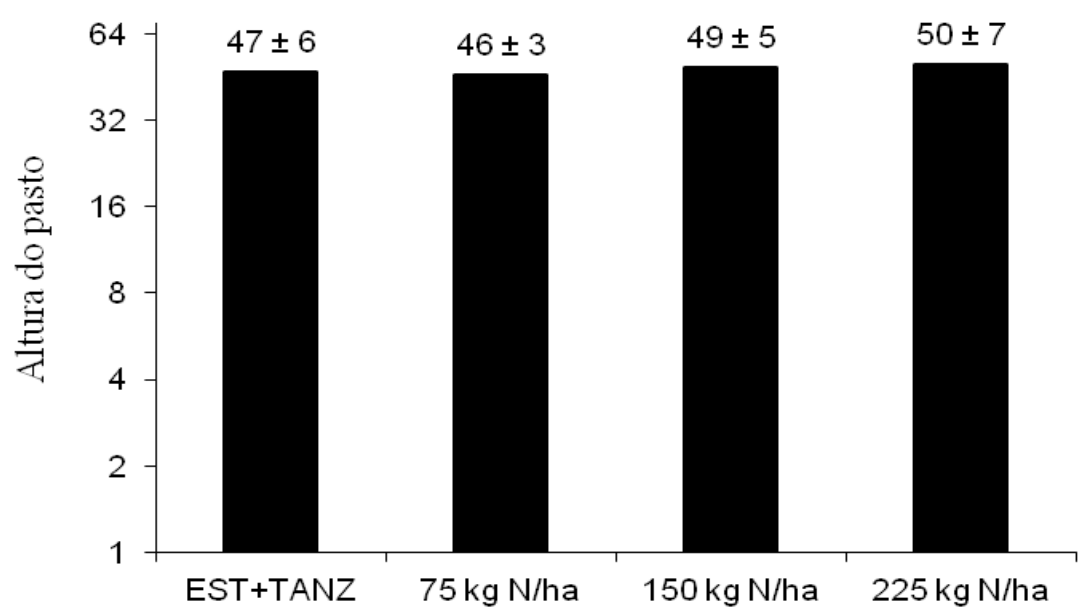

Fonte: Dados coletados durante o período experimental.

No início do experimento, os animais foram tratados com Ivermectina 1\% para controle de endoparasitos e ectoparasitos. Os animais receberam suplemento mineral comercial (ad libitum) com a seguinte composição por quilo: $89 \mathrm{~g}$ de $\mathrm{Ca} ; 65 \mathrm{~g}$ de P; 10 g de S; 125 g de Na; 44 mg de Co; 1213 mg de $\mathrm{Cu} ; 1900 \mathrm{mg}$ de Fe; 60 mg de I; 1189 mg de Mn; 10 mg de Se; 2880 mg de Zn e 649 mg de F.

Para estimativa da massa seca de forragem (MSF) e massa seca de lâminas foliares (MSLF), foi utilizado o método da dupla amostragem descrito por GARDNER (1986). Realizaram-se 15 avaliações por piquete, sendo dez estimativas visuais e cinco reais (cortes) a $5 \mathrm{~cm}$ do solo, ao acaso, a cada 28 dias, utilizando-se um quadrado metálico com área de $1 \mathrm{~m}^{2}$. Do material coletado, uma subamostra foi retirada e separada nas seguintes frações: lamina foliar verde, colmo+bainha verde, material morto e estilosantes (planta inteira). O material coletado e as frações lamina foliar foram secos em estufa a $55^{\circ} \mathrm{C}$ (ventilação forçada) por $72 \mathrm{~h}$, e em seguida moídos em moinho tipo Willey com peneira de $1 \mathrm{~mm}$. Os valores de MSF e MSLF foram convertidos para $\mathrm{kg}$ de MS ha ${ }^{-1}$.

Posteriormente, foram analisados os teores de: matéria seca (MS) em estufa a $105^{\circ} \mathrm{C}$; proteína bruta (PB) pelo método micro Kjeldhal (AOAC, 1990); fibra em detergente neutro (FDN) pelo método de partição de fibras proposta por Van Soest, Robertson e Lewis (1991) utilizando o aparelho ANKOM $^{\circledR}$ Fiber Analyser; digestibilidade in vitro da matéria seca (DIVMS) de acordo com a metodologia de Tilley e Terry (1963), adaptada para a utilização do rúmen artificial (Daisy in vitro Incubator ANKOM Technology), conforme descrito por Garman, Holden e Kane (1997). 
O desempenho animal foi avaliado pelo ganho médio diário (GMD), estimado pela diferença de peso dos animais testes no início e ao final do experimento, em jejum, dividido pelo número de dias que os mesmos permaneceram na pastagem, sendo os animais pesados em intervalos de 28 dias, em jejum de sólidos de 18 horas. Foi estimado o ganho de peso vivo por ha (GPV ha ${ }^{-1} \mathrm{dia}^{-1}$ ) por meio do produto do número de animais $\mathrm{ha}^{-1} \mathrm{dia}^{-1} \mathrm{e}$ o ganho diário médio dos animais testes. A taxa de lotação (TL) por hectare $\left(\right.$ UA.ha $\left.^{-1}\right)$ foi calculada a partir do peso médio dos reguladores, multiplicado pelo número de dias que os mesmos permaneceram na pastagem, dividido pelo número de dias do período, somando-se o peso médio dos animais testes, estimados por meio do quociente do ganho de peso vivo/ha, pela unidade animal (450 $\mathrm{kg}$ de $\mathrm{PV}=1 \mathrm{UA})$.

A análise da variância foi realizada por meio do programa Sistema de Análises Estatísticas e Genéticas - SAEG (RIBEIRO JÚNIOR, 2001), segundo o modelo:

$$
\mathrm{Y}_{\mathrm{ijk}}=\mu+\mathrm{T}_{\mathrm{i}}+\mathrm{P}_{\mathrm{j}}+\mathrm{B}_{\mathrm{k}}+\mathrm{TP}_{\mathrm{ij}}+\mathrm{e}_{\mathrm{ijk}}
$$

Em que, Yijk = valor da variável observada no piquete que recebeu o tratamento $i$, coletada no período $\mathrm{j}$ e encontrava-se no bloco $\mathrm{k} ; \mu=$ média geral; $\mathrm{Ti}=$ efeito do tratamento, com $\mathrm{i}$ variando de $1 \mathrm{a} 4 ; \mathrm{Pj}=$ efeito devido ao período, com $\mathrm{j}$ variando de 1 a $4 ; \mathrm{Bk}=$ efeito devido ao bloco, com $\mathrm{k}$ variando de 1 a 3; TPij=é o efeito da interação entre tratamento e período; eijk = erro aleatório associado a cada observação. As médias foram submetidas ao teste Tukey a $5 \%$ de probabilidade.

\section{Resultados e Discussão}

Houve diferença na massa seca de forragem (MSF) entre os tratamentos e entre as estações do ano avaliadas $(\mathrm{P}<0,05)$, no entanto, não houve interação $(\mathrm{P}>0,05)$ entre tratamentos e estações (Tabela 2). Os pastos adubados com a maior dose de $\mathrm{N}$ apresentaram maior produção de MSF, evidenciando que o uso de nitrogênio no sistema, associado à condições adequadas de umidade, temperatura e luminosidade promove o incremento da produção de massa seca de forragem das pastagens.

Os pastos consorciados com estilosantes Campo Grande apresentaram MSF similar aos com 75 e $150 \mathrm{~kg}$ de $\mathrm{N} \mathrm{ha}^{-1} \mathrm{ano}^{-1}$ (Tabela 2). Este resultado comprova a eficiência da fixação biológica de $\mathrm{N}$ pelas leguminosas, assim como, sua reciclagem e transferência para a gramínea. Miranda, Fernandes e Cadish (1999) afirmaram que o estilosantes pode fixar de 88 a $180 \mathrm{~kg}$ de $\mathrm{N} \mathrm{ha}^{-1}$ ano $^{-1}$. Outro fator importante, segundo Paciullo et al. (2003), o cultivo de gramíneas em consórcio com leguminosas melhora e diversifica a dieta oferecida ao animal.

Tabela 2. Massa seca de forragem e de lâmina foliar de capim-Tanzânia consorciado ou adubado com doses de nitrogênio $(\mathrm{N})$ nas estações do ano.

\begin{tabular}{|c|c|c|c|c|}
\hline \multirow{3}{*}{ Tratamentos } & & eríodos do An & & \multirow{3}{*}{ Média } \\
\hline & Primavera & Verão & Outono & \\
\hline & \multicolumn{3}{|c|}{ Massa seca de forragem (kg/ha) } & \\
\hline Estilosantes & $4678 \pm 513 *$ & $6276 \pm 1437$ & $4004 \pm 535$ & $4401 \mathrm{~B}$ \\
\hline $75 \mathrm{~kg}$ de $\mathrm{N}$ & $4658 \pm 635$ & $6112 \pm 1428$ & $4726 \pm 170$ & $4764 \mathrm{~B}$ \\
\hline $150 \mathrm{~kg}$ de $\mathrm{N}$ & $6105 \pm 1509$ & $6170 \pm 1275$ & $4968 \pm 1448$ & $5244 \mathrm{~B}$ \\
\hline $225 \mathrm{~kg}$ de $\mathrm{N}$ & $7045 \pm 1201$ & $8650 \pm 274$ & $6667 \pm 640$ & $6702 \mathrm{~A}$ \\
\hline \multirow[t]{2}{*}{ Média } & $5622 \mathrm{~b}$ & $6802 \mathrm{a}$ & $5091 \mathrm{~b}$ & \\
\hline & \multicolumn{3}{|c|}{ Massa seca de lâmina foliar (kg/ha) } & \\
\hline Estilosantes & $2346 \pm 306$ & $2119 \pm 534$ & $1225 \pm 83$ & $1916 \mathrm{~B}$ \\
\hline $75 \mathrm{~kg}$ de $\mathrm{N}$ & $2742 \pm 670$ & $2580 \pm 502$ & $1730 \pm 131$ & $2088 \mathrm{~B}$ \\
\hline $150 \mathrm{~kg}$ de $\mathrm{N}$ & $3888 \pm 816$ & $2803 \pm 162$ & $2044 \pm 526$ & $2208 \mathrm{~A}$ \\
\hline $225 \mathrm{~kg}$ de $\mathrm{N}$ & $4073 \pm 715$ & $3898 \pm 255$ & $2663 \pm 135$ & $2290 \mathrm{~A}$ \\
\hline Média & $3262 \mathrm{a}$ & $2850 \mathrm{~b}$ & $1916 \mathrm{c}$ & \\
\hline
\end{tabular}

Letras iguais, maiúscula nas colunas e minúsculas nas linhas, não diferem pelo teste Tukey $(\mathrm{P}<0,05)$. ${ }^{*}$ Desvio padrão da média. Fonte: Elaboração dos autores. 
Dentre as estações do ano avaliadas, no verão houve maior produção de $\operatorname{MSF}(\mathrm{P}<0,05)$, independente do consórcio ou das doses de $\mathrm{N}$ utilizadas (Tabela 2). Tal fato se deve às condições climáticas favoráveis observadas durante as estações (Figura 1) e também ao aumento na quantidade de horas luz.dia ${ }^{-1}$, favorecendo o processo de fotossíntese.

Não houve diferença $(\mathrm{P}>0,05)$ na produção de MSF entre a primavera e o outono (Tabela 2). A produção de MSF da primavera foi favorecida pelo fato da pastagem ter passado por um período de descanso (vedada) no inverno. Já a produção elevada no outono, provavelmente foi pelo efeito residual da adubação nitrogenada nas estações anteriores. Euclides et al. (2007) afirmaram que a aplicação da adubação nitrogenada no período de transição água-seca pode aumentar a produção de forragem no outono, permitindo que nessa estação sejam alcançados níveis de produção satisfatórios.

Com relação à produção de massa seca de lâmina foliar (MSLF), houve diferença entre os tratamentos e entre as estações do ano avaliadas $(\mathrm{P}<0,05)$, no entanto não houve interação $(\mathrm{P}>0,05)$ entre tratamentos e estações (Tabela 2). O uso de 150 e $225 \mathrm{~kg}$ de $\mathrm{N}^{-1}$ ano $^{-1}$ propiciou maior produção de MSLF. Este resultado corrobora com os de Paris et al. (2009), que verificaram um aumento da disponibilidade de folhas com o uso da adubação nitrogenada. No que concerne às estações avaliadas, a maior produção de lâmina foliar (MSLF) foi obtida na primavera (Tabela 2). Isso provavelmente ocorreu pela vedação da pastagem durante o inverno.

No que diz respeito ao valor nutritivo da forragem ( $\% \mathrm{~PB}, \% \mathrm{FDN}$ e $\% \mathrm{DIVMS})$, ao comparar os tratamentos, apenas houve diferença $(\mathrm{P}<0,05)$ no teor de proteína bruta $(\% \mathrm{~PB})$ do capim-Tanzânia, tanto da lâmina foliar quanto do colmo+bainha (Tabela 3). O pasto que recebeu $225 \mathrm{~kg}$ de $\mathrm{N} \mathrm{ha}^{-1}$ $\mathrm{ano}^{-1}$ apresentou lâminas foliares com maior teor proteico, evidenciando a contribuição da adubação nitrogenada no incremento do teor proteico nas pastagens, e com isso na dieta dos animais.

\section{O capim-Tanzânia em consórcio com estilosantes} Campo Grande apresentou teor proteico (lâmina foliar e bainha+colmo) semelhante ao tratamento que recebeu $75 \mathrm{~kg}$ de $\mathrm{N}^{-1}$ ano $^{-1}$, evidenciando o efeito positivo do consórcio ao sistema.

De acordo com Van Soest (1994), dietas com níveis abaixo de $7 \%$ de $\mathrm{PB}$ na $\mathrm{MS}$ reduzem a atividade de microbiana no rúmen, e com isso a taxa de digestão de celulose é prejudicada, levando à um aumento no tempo de retenção da forragem no rúmen e um decréscimo no consumo voluntário de forragem. Em outras palavras, teor proteico abaixo de 7 \% MS não supre o requisito proteico de mantença do animal, levando assim à perda de peso. No entanto, em todas as situações do presente estudo as folhas do capim-Tanzânia apresentaram teor proteico superior a $8,4 \%$, evidenciando um bom manejo do pasto e a contribuição do nitrogênio presente na forragem para um bom desempenho dos animais (Tabela 5).

A ausência de diferença $(\mathrm{P}>0,05)$ no teor de fibra em detergente neutro (FDN) nas frações lâmina foliar e colmo+bainha entre os tratamentos pode justificar a ausência de diferença na \%DIVMS desses constituintes, uma vez que nesta fração fibrosa (FDN) está inserida a celulose, componente determinante da digestibilidade da dieta e, ou, forragem. Ausência de diferença no teor de FDN ao avaliarem o capim-Tanzânia adubado com diferentes doses de nitrogênio e fósforo também foi observada por Patês et al. (2008), corroborando assim com o resultado do presente estudo. 
Tabela 3. Composição química de lâmina foliar e colmo + bainha do capim-Tanzânia consorciado ou adubado com nitrogênio nas estações do ano.

\begin{tabular}{|c|c|c|c|c|c|}
\hline \multirow{4}{*}{ Períodos } & \multicolumn{4}{|c|}{ Tratamentos } & \multirow{4}{*}{ Média } \\
\hline & Estilosantes & $75 \mathrm{~kg}$ de $\mathrm{N}$ & $150 \mathrm{~kg}$ de $\mathrm{N}$ & $225 \mathrm{~kg}$ de $\mathrm{N}$ & \\
\hline & \multicolumn{4}{|c|}{$\%$ Proteína bruta } & \\
\hline & \multicolumn{4}{|c|}{ Lâmina foliar } & \\
\hline Primavera & $7,8 \pm 0,3^{*}$ & $8,6 \pm 0,5$ & $9,2 \pm 0,3$ & $9,7 \pm 0,9$ & $8,8 \mathrm{~B}$ \\
\hline Verão & $8,1 \pm 0,6$ & $7,9 \pm 0,5$ & $9,0 \pm 1,0$ & $10,0 \pm 0,4$ & $8,7 \mathrm{~B}$ \\
\hline Outono & $9,0 \pm 0,5$ & $9,9 \pm 0,7$ & $10,5 \pm 1,4$ & $11,1 \pm 0,2$ & $10,1 \mathrm{~A}$ \\
\hline Média & $8,4 \mathrm{c}$ & $8,8 \mathrm{bc}$ & $9,4 \mathrm{~b}$ & $10,3 \mathrm{a}$ & \\
\hline \multicolumn{6}{|c|}{ Colmo + bainha } \\
\hline Primavera & $4,4 \pm 0,3$ & $5,0 \pm 0,7$ & $5,0 \pm 0,1$ & $5,4 \pm 0,3$ & $5,0 \mathrm{~A}$ \\
\hline Verão & $4,2 \pm 0,2$ & $4,2 \pm 0,5$ & $4,7 \pm 0,6$ & $5,0 \pm 0,1$ & $4,5 \mathrm{AB}$ \\
\hline Outono & $4,1 \pm 0,3$ & $4,7 \pm 0,3$ & $4,9 \pm 0,6$ & $4,9 \pm 0,3$ & $4,7 \mathrm{~A}$ \\
\hline Média & $4,1 \mathrm{~b}$ & $4,5 \mathrm{ab}$ & $4,7 \mathrm{a}$ & $5,0 \mathrm{a}$ & \\
\hline \multicolumn{6}{|c|}{$\%$ Fibra em detergente neutro } \\
\hline \multicolumn{6}{|c|}{ Lâmina foliar } \\
\hline Primavera & $72,3 \pm 0,6$ & $71,2 \pm 1,8$ & $71,0 \pm 0,9$ & $70,9 \pm 1,7$ & $71,4 \mathrm{AB}$ \\
\hline Verão & $72,6 \pm 1,5$ & $73,0 \pm 0,3$ & $73,5 \pm 2,0$ & $71,8 \pm 0,8$ & $72,7 \mathrm{~A}$ \\
\hline Outono & $69,9 \pm 1,7$ & $69,9 \pm 0,7$ & $69,7 \pm 1,5$ & $60,2 \pm 0,8$ & $67,4 \mathrm{~B}$ \\
\hline Média & 70,5 & 70,8 & 70,5 & 67,5 & \\
\hline \multicolumn{6}{|c|}{ Colmo + bainha } \\
\hline Primavera & $76,4 \pm 1,6$ & $76,6 \pm 0,7$ & $72,4 \pm 7,4$ & $75,0 \pm 1,9$ & 75,0 \\
\hline Verão & $77,1 \pm 1,3$ & $76,7 \pm 1,2$ & $77,1 \pm 1,1$ & $76,5 \pm 0,7$ & 77,0 \\
\hline Outono & $75,7 \pm 2,3$ & $79,8 \pm 3,9$ & $75,5 \pm 1,4$ & $77,2 \pm 0,5$ & 77,1 \\
\hline Média & 76,1 & 77,2 & 75,0 & 76,0 & \\
\hline \multicolumn{6}{|c|}{$\%$ Digestibilidade in vitro } \\
\hline \multicolumn{6}{|c|}{ Lâmina foliar } \\
\hline Primavera & $55,9 \pm 7,62$ & $52,6 \pm 2,9$ & $53,4 \pm 1,2$ & $53,0 \pm 2,6$ & $54,0 \mathrm{C}$ \\
\hline Verão & $64,3 \pm 4,0$ & $62,4 \pm 6,0$ & $62,0 \pm 3,5$ & $59,0 \pm 0,4$ & $62,0 \mathrm{~B}$ \\
\hline Outono & $68,9 \pm 2,8$ & $70,0 \pm 2,7$ & $68,2 \pm 6,6$ & $68,0 \pm 3,1$ & $68,6 \mathrm{~A}$ \\
\hline Média & 66,0 & 64,2 & 63,6 & 63,0 & \\
\hline \multicolumn{6}{|c|}{ Colmo + bainha } \\
\hline Primavera & $52,9 \pm 4,8$ & $49,2 \pm 1,4$ & $51,4 \pm 4,0$ & $50,4 \pm 0,7$ & $51,0 \mathrm{C}$ \\
\hline Verão & $62,1 \pm 0,6$ & $58,1 \pm 1,4$ & $61,5 \pm 2,6$ & $60,3 \pm 1,5$ & $60,5 \mathrm{~B}$ \\
\hline Outono & $63,0 \pm 1,4$ & $64,0 \pm 1,7$ & $63,0 \pm 2,3$ & $61,0 \pm 1,6$ & $63,0 \mathrm{~A}$ \\
\hline Média & 61,0 & 60,0 & 60,3 & 59,0 & \\
\hline
\end{tabular}

Letras iguais, maiúscula nas colunas e minúsculas nas linhas, não diferem pelo teste Tukey $(\mathrm{P}<0,05)$.

*Desvio Padrão da Média.

Fonte: Elaboração dos autores. 
Tabela 4. Composição química do estilosantes Campo Grande nas estações do ano.

\begin{tabular}{lccc}
\hline \multirow{2}{*}{ Períodos } & \multicolumn{3}{c}{ Estilosantes Planta Inteira } \\
\cline { 2 - 4 } & PB $^{1}$ & FDN $^{1}$ & DIVMS $^{1}$ \\
\hline Primavera & $11,7 \pm 0,4^{*} \mathrm{~A}$ & $67,4 \pm 1,4 \mathrm{~B}$ & $54,0 \pm 8,1$ \\
Verão & $11,8 \pm 0,4 \mathrm{~A}$ & $66,9 \pm 1,7 \mathrm{~B}$ & $54,0 \pm 1,3$ \\
Outono & $9,8 \pm 1,2 \mathrm{~B}$ & $71,1 \pm 1,3 \mathrm{~A}$ & $50,3 \pm 0,9$ \\
\hline Média & 10,8 & 69,1 & 53,0 \\
\hline
\end{tabular}

Letras iguais, maiúscula nas colunas e minúsculas nas linhas, não diferem pelo teste Tukey $(\mathrm{P}<0,05)$

${ }^{1}$ Proteína bruta (PB), fibra em detergente neutro (FDN), digestibilidade in vitro da matéria seca (DIVMS)

*Desvio padrão da Média

Fonte: Elaboração dos autores.

Com relação às estações do ano avaliadas, houve diferença $(\mathrm{P}<0,05)$ no teor de PB, FDN e DIVMS em ambos constituintes morfogênicos avaliados (frações LF e CB), com excessão para o teor de PB e FDN na fração colmo+bainha que não apresentou diferença $(\mathrm{P}>0,05)$ entre as estações (Tabela 3$)$.

O outono foi a estação na qual o capim-Tanzânia apresentou maior $(\mathrm{P}<0,05)$ teor proteico na lâmina foliar (Tabela 3). Isso possivelmente devido às boas condições de temperatura e preciptação e, pelo fato de no início desta estação ter sido realizada a terceira aplicação da adubação nitrogenada. Nesta terceira aplicação foi utilizado o nitrato de amônio de forma estratégica, uma vez que o nitrogênio presente neste composto químico é menos volátil quando comparado à ureia. Desta forma, o nitrogênio apresenta um efeito residual no sistema, sendo utilizado pelas plantas de forma gradativa, minimizando as perdas por volatilidade e prolongando a qualidade da planta forrageira ao adentrar as estações de características adversas, como seca e, ou, baixas temperaturas.

Como supracitado, houve diferença $(\mathrm{P}<0,05)$ no teor de FDN apenas na fração lâmina foliar. Os maiores valores para este constituinte foram observados na primavera e no verão (Tabela 3). De acordo com Medeiros et al. (2007), existem interações entre temperatura e fotoperíodo (número de horas luz.dia ${ }^{-1}$ ) que determinam a produção de MS, uma vez que a produção de forragem é maior nas estações primavera e verão (quente/chuvosa) e reduzido nas estações outono e inverno (frio/seca), podendo até ser nula. Ademais, o número de horas luz.dia ${ }^{-1}$ é fator determinante no que diz respeito ao processo de fotossíntese das plantas. Ao considerar a ordem cronológica das estações primavera, verão e outono, e as características edafoclimáticas em cada uma delas, é possível perceber o aumento do teor de FDN na fração LM, com valor máximo no verão, e decréscimo no outono (Tabela 3). Esse mesmo comportamento foi observado para a produção de MS de lâmina foliar no presente estudo (Tabela 2), corroborando com as afirmações de Medeiros et al. (2007).

Portanto, fotoperíodo longo, característico do verão brasileiro, favorece o processo fotossintético das plantas, fazendo com que haja uma maior taxa de alongamento foliar e, desta forma, há um incremento no teor de componentes estruturais das folhas para manter a arquitetura do dossel forrageiro, neste caso, a fibra em detergente neutro.

Quanto à digestibilidade in vitro da materia seca (DIVMS), houve melhora $(\mathrm{P}<0,05)$ desta variável em ambas estruturas morfogênicas (LM e CB) no decorrer das estações avaliadas, ou seja, menor valor na primavera e maior valor no outono (Tabela 3). Esses resultados demonstram um comportamento que é natural e cíclico no que diz respeito ao processo de maturidade fisiológica das plantas forrageiras.

Embora durante o inverno, a pastagem não tenha sido avaliada (utilizada) no presente estudo devido à limitação de produção de MS, é de conhecimento 
que nesta estação há um aumento no processo de lignificação das plantas, atingindo o maior teor de lignina durante a primavera. Este constituinte limita a digestibilidade dos constituintes da parede celular (celulose e hemicelulose), e desta forma reduz a digestibilidade das estruturas morfogênicas e da planta como um todo (BAUER et al., 2008). Estes autores observaram um coeficiente de correlação negativa e linear $(-0,89)$ entre o teor de lignina e a DIVMS.

Ao avaliarem algumas características de valor nutritivo de três gramíneas tropicais (Marandu, Setária e Tanzânia), Gerdes et al. (2000), no que diz respeito à DIVMS da lâmina foliar, colmo e planta inteira do Capim-Tanzânia, observaram o mesmo comportamento estacional (cíclico) apresentado neste estudo, ou seja, maior DIVMS nas estações outono, verão, inverno e primavera, respectivamente.

O estilosantes apresentou PB superior na primavera everão (Tabela4). Isso possivelmente pela maior quantidade de folha presente na planta nessas estações. Confirmando assim, a hipótese de que o consórcio de leguminosa com gramínea melhora o desempenho animal por meio da manutenção do nível adequado de PB na dieta (BARCELLOS et al., 2008; PARIS et al., 2009).

A FDN do estilosantes foi menor na primavera e no verão em razão da grande porcentagem de planta jovem no sistema oriunda do ressemeio que foi feito na estação anterior. $O$ teor de fibra mais elevado no outono não foi suficiente para alterar a digestibilidade do estilosantes.

$\mathrm{Na}$ Tabela 5, os dados mostram que houve interação entre o pasto consorciado e os adubados com $\mathrm{N}$ e estações do ano sobre o ganho médio diário (GMD). No outono, as condições climáticas não favoreceram a produção de massa de forragem, portanto, o pasto consorciado e com menor dose de nitrogênio tiveram menor taxa de lotação, estimulando com isso, a seletividade do animal durante o pastejo e consequentemente aumentando o ganho médio diário. Paciullo et al. (2008) narraram que devido a redução da precipitação, temperatura e da radiação solar no outono, geralmente, ocorre redução na oferta e qualidade da forragem, refletindo diretamente sobre o desempenho animal, fato esse, ocorrido no presente estudo.

Independente do consórcio ou das doses de $\mathrm{N}$ utilizadas, o GMD foi maior na primavera e verão. Isso possivelmente devido à maior produção de MSLF e produção MSF (Tabela 2) que ocorreram na primavera e verão. Barbosa, Nascimento Júnior e Cecato (2006) relataram que um bom desempenho animal pode ser explicado pelo melhor equilíbrio entre boa disponibilidade de lâminas verdes, altura da pastagem e baixa quantidade de material morto.

Os maiores GMD durante o outono foram observados no consórcio e $75 \mathrm{~kg} \mathrm{~N} \mathrm{ha}^{-1}$. Esse fato é explicado pela diminuição na carga animal utilizada durante o período, possibilitando assim aos animais maior possibilidade de seleção da dieta.

O GMD observado nos pastos adubados com 150 e $225 \mathrm{~kg} \mathrm{~N} \mathrm{ha}^{-1}$ foi superior aos demais na primavera e verão. Isto se deve, em parte, ao benefício que o nitrogênio causa no valor nutritivo das plantas forrageiras. Segundo Brâncio et al. (2002), a utilização de adubação nitrogenada promove aumento no teor de proteína bruta e redução no conteúdo de lignina e sílica das forrageiras. Esses fatores propiciam ao animal um ambiente pastoril mais favorável por apresentarem uma estrutura de relvado mais apropriada para apreensão de forragem pelo mesmo. 
Tabela 5. Desempenho animal em pastagem de capim-Tanzânia consorciado ou adubado com doses de nitrogênio nas estações do ano.

\begin{tabular}{|c|c|c|c|c|}
\hline \multirow{3}{*}{ Tratamentos } & & Períodos do $\mathrm{A}$ & & \multirow{3}{*}{ Média } \\
\hline & Primavera & Verão & Outono & \\
\hline & \multicolumn{3}{|c|}{ Ganho médio diário (kg/dia) } & \\
\hline Estilosantes & $0,71 \pm 0,10^{*}$ & $0,89 \pm 0,09$ & $0,92 \pm 0,16 \mathrm{~A}$ & 0,84 \\
\hline $75 \mathrm{~kg}$ de $\mathrm{N}$ & $0,86 \pm 0,07$ & $0,92 \pm 0,04$ & $0,79 \pm 0,24 \mathrm{~A}$ & 0,86 \\
\hline $150 \mathrm{~kg}$ de $\mathrm{N}$ & $0,86 \pm 0,03 \mathrm{a}$ & $1,05 \pm 0,09 \mathrm{a}$ & $0,44 \pm 0,23 \mathrm{Bb}$ & 0,78 \\
\hline $225 \mathrm{~kg}$ de N & $0,86 \pm 0,02 \mathrm{a}$ & $1,04 \pm 0,07 \mathrm{a}$ & $0,62 \pm 0,34 \mathrm{Bb}$ & 0,84 \\
\hline \multirow[t]{2}{*}{ Média } & $0,82 \mathrm{ab}$ & $0,97 \mathrm{a}$ & $0,69 \mathrm{~b}$ & \\
\hline & \multicolumn{3}{|c|}{ Taxa de lotação (UA/ha) } & \\
\hline Estilosantes & $2,24 \pm 0,24$ & $2,07 \pm 0,06$ & $2,48 \pm 0,11$ & $2,26 \mathrm{~B}$ \\
\hline $75 \mathrm{~kg}$ de $\mathrm{N}$ & $2,18 \pm 0,55$ & $2,26 \pm 0,24$ & $2,55 \pm 0,10$ & $2,33 \mathrm{~B}$ \\
\hline $150 \mathrm{~kg}$ de $\mathrm{N}$ & $2,45 \pm 0,45$ & $2,80 \pm 0,63$ & $2,61 \pm 0,04$ & $2,62 \mathrm{~A}$ \\
\hline $225 \mathrm{~kg}$ de $\mathrm{N}$ & $3,07 \pm 0,73$ & $3,45 \pm 0,88$ & $2,77 \pm 0,23$ & $3,10 \mathrm{~A}$ \\
\hline \multirow[t]{2}{*}{ Média } & 2,48 & 2,65 & 2,60 & \\
\hline & \multicolumn{3}{|c|}{ Ganho de peso vivo (kg/ha) } & \\
\hline Estilosantes & $364,80 \pm 0,35$ & $421,80 \pm 0,24 \mathrm{~B}$ & $517,56 \pm 0,38$ & 434,72 \\
\hline $75 \mathrm{~kg}$ de $\mathrm{N}$ & $428,64 \pm 0,44$ & $478,8 \pm 0,26 \mathrm{~B}$ & $462,84 \pm 0,71$ & 456,76 \\
\hline $150 \mathrm{~kg}$ de $\mathrm{N}$ & $481,08 \pm 0,40 \mathrm{a}$ & $679,44 \pm 0,88 \mathrm{Aa}$ & $259,92 \pm 0,59 \mathrm{~b}$ & 473,48 \\
\hline $225 \mathrm{~kg}$ de $\mathrm{N}$ & $597,36 \pm 0,58 \mathrm{a}$ & $823,08 \pm 1,14 \mathrm{Aa}$ & $401,28 \pm 1,05 b$ & 607.24 \\
\hline Média & $467,97 \mathrm{ab}$ & $600,78 \mathrm{a}$ & $410,4 \mathrm{~b}$ & \\
\hline
\end{tabular}

Letras iguais, maiúscula nas colunas e minúsculas nas linhas, não diferem pelo teste Tukey $(\mathrm{P}<0,05)$.

*Desvio padrão da média.

Fonte: Elaboração dos autores.

Não houve interação entre os tratamentos e os períodos quando foi avaliado a taxa de lotação (TL), bem como também não se verificou diferença $(\mathrm{P}>0,05)$ entre as estações avaliadas, porém houve efeito $(\mathrm{P}<0,05)$ entre os tratamentos. Foi observada maior taxa de lotação quando foram utilizadas as maiores doses de adubação nitrogenada, ficando evidente que o $\mathrm{N}$ aumenta a capacidade de suporte das pastagens, no entanto diminuem o desempenho individual do animal, como pode ser visto no GMD dos pastos com 150 e $225 \mathrm{~kg} \mathrm{~N} \mathrm{ha}^{-1}$. Isso implica dizer que quanto maior a taxa de lotação menor o ganho por animal, pois os animais diminuem a eficiência de pastejo devido ao grande número de animais na área. Por outro lado, o ganho por unidade de área aumenta, uma vez que, a quantidade de animais é maior na mesma área.

Não houve diferença $(\mathrm{P}<0,05)$ na taxa de lotação entre o consórcio com estilosantes e a menor dose de $\mathrm{N}$ utilizada, evidenciando assim, o incremento que a leguminosa em consórcio com gramíneas permite ao sistema.

O ganho de peso vivo por área (GPV) foi superior na primavera e no verão quando comparado ao outono. Isto possivelmente se deve ao maior GMD obtido naqueles períodos. Outro fator a ser levado em consideração foi a maior produção de MSF (Tabela 2) nas referidas estações.

$\mathrm{Na}$ interação entre os tratamentos e estações do ano ficou evidente que no outono os pastos adubados com 150 e $225 \mathrm{~kg} \mathrm{~N} \mathrm{ha}{ }^{-1}$ proporcionaram GPV inferiores. Segundo Paciullo et al. (2008), no outono, os índices climáticos contribuem negativamente com a oferta e qualidade da forragem, fator esse que pode ter contribuído para diminuição do GPV no presente estudo. Outros fatores a serem levados em consideração para menor GPV foram os menores GMD no período, decorrente do aumento da taxa de lotação. 


\section{Conclusões}

O consórcio com estilosantes e as doses menores de nitrogênio não influenciam a composição química do capim-Tanzânia, exceto na dose maior (225 $\mathrm{kg} \mathrm{N} \mathrm{ha}^{-1}$ ) em que a proteína bruta da lâmina foliar foi mais elevada.

O desempenho animal não varia em função do consórcio e da adubação, todavia melhora nas estações de primavera e verão, em que as condições climáticas favorecem a produção de massa de lâminas e de forragem. Dessa forma, a inclusão de leguminosas no sistema pecuário diminui a dependência do uso excessivo de fertilizantes nitrogenados e contribui no desempenho animal.

\section{Referências}

ANDRADE, C. M. S.; VALENTIM, J. F.; CARNEIRO, J. C. VAZ, F. A. Crescimento de gramíneas e leguminosas forrageiras sob sombreamento. Pesquisa Agropecuária Brasileira, Brasília, v. 39, n. 3, p. 263-270, 2004.

ANUÁRIO DA PECUÁRIA BRASILEIRA ANUALPEC. Informa economics. 20. ed. São Paulo: FNP, 2013. $357 \mathrm{p}$.

ASSOCIATION OF OFFICIAL ANALYTICAL CHEMISTS - AOAC. Official methods of analysis.15. ed. Gaithersburg: Richmond, 1990. 1298 p.

BARBOSA, M. A. A. F.; NASCIMENTO JUNIOR, D.; CECATO, U. Dinâmica da pastagem e desempenho de novilhos em pastagem de capim-Tanzânia sob diferentes ofertas de forragem. Revista Brasileira de Zootecnia, Viçosa, MG, v. 35, n. 4, p. 1594-1600, 2006.

BARCELLOS, A. O.; RAMOS, A. K. B.; VILELA, L.; MARTHA JÚNIOR, G. B. Sustentabilidade da produção animal baseada em pastagens consorciadas e no emprego de leguminosas exclusivas, na forma de banco de proteína, nos trópicos brasileiros. Revista Brasileira de Zootecnia, Viçosa, MG, v. 37, p. 51-67, 2008. Suplemento especial.

BAUER, M. O.; GOMIDE, J. A.; SILVA, E. A. M.; REGAZZI, A. J.; CHICHORRO, J. F. Características anatômicas e valor nutritivo de quatro gramíneas predominantes em pastagem natural de Viçosa, MG. Revista Brasileira de Zootecnia, Viçosa, MG, v. 37, n. 1, p. 9-17, 2008.

BRÂNCIO, P. A.; NASCIMENTO JÚNIOR, D. do; EUCLIDES, V. P. B.; REGAZZI, A. J.; ALMEIDA, R.
G.; FONSECA, D. M.; BARBOSA, R. A. Avaliação de três cultivares de Panicum maximum Jacq. sob pastejo. Composição química e digestibilidade da forragem. Revista Brasileira de Zootecnia, Viçosa, MG, v. 31, n. 4, p. 1605-1613, 2002.

EMPRESA BRASILEIRA DE PESQUISA AGROPECUÁRIA - EMBRAPA. Sistema brasileiro de classificação de solos. Brasília: Centro Nacional de Pesquisa de Solos, 1999. 412 p.

EUCLIDES, V. P. B.; COSTA, F. P.; MACEDO, M. C. M.; FLORES, R.; OLIVEIRA, M. P. Eficiência biológica e econômica de pasto de capim-Tanzânia adubado com nitrogênio no final do verão. Pesquisa Agropecuária Brasileira, Brasília, v. 42, n. 9, p. 1345-1355, 2007.

GARCIA, C. S.; FERNANDES, A. M.; FONTES, C. A. A.; VIEIRA, R. A. M.; SANT'ANA, N. F.; PIMENTEL, V. A. Desempenho de novilhos mantidos em pastagens de capim-elefante e capim-mombaça. Revista Brasileira de Zootecnia, Viçosa, MG, v. 40, n. 2, p. 403-410, 2011.

GARDNER, A. L. Técnicas de pesquisa em pastagens e aplicabilidade de resultadosem sistemas de produção. Brasília: IICA, 1986. 197 p.

GARMAN, C. L.; HOLDEN, L. A.; KANE, H. A. Comparison of in vitro dry matter digestibility of nine feedstufs using three methods of analysis. Journal of Dairy Science, Madison, v. 80, p. 260, 1997. Supplement 1.

GERDES, L.; WERNER, J. C.; COLOZZA, M. T.; POSSENTI, R. A.; SCHAMMASS, E. A. Avaliação de características de valor nutritivo das gramíneas forrageiras marandu, setária e Tanzânia nas estações do ano. Revista Brasileira de Zootecnia, Viçosa, MG, v. 29, n. 4, p. 955-963, 2000.

LUDLOW, M. M. Light relations of pastures plants. En: Plant relation in pastures. WILSON, J. R. (Ed.). Commonwealth scientific and industrial research organisation (CSIRO). Australia: East Melbourne, 1987. p. 35-49.

MARTHA JÚNIOR, G. B.; CORSI, M. Pastagens no Brasil: situação atual e perspectivas. Preços Agrícolas, Florianópolis, v. 171, p. 3-6, 2001.

MEDEIROS, H. R.; PEDREIRA, C. G. S.; VILLA NOVAJ, N. A.; MELLOY, E. A. C. L. Temperatura base de gramíneas forrageiras estimada através do conceito de unidade fototérmica. Pasturas Tropicales, Colômbia, v. 29, n. 1, p. 82-86, 2007.

MIRANDA, C. B. H.; FERNANDES, C. D.; CADISH, G. Quantifying the fixed by Stylosanthes. Pasturas Tropicales, Colômbia, v. 21, n. 1, p. 64-69, 1999. 
MOTT, G. O.; LUCAS, H. L. The design, conduct and interpretation of grazing trials on cultivated and improved pastures. In: INTERNATIONAL GRASSLAND CONGRESS, 6., 1952, Pasadena. Proceedings... Pasadena, 1952. p. 1380-1385.

PACIULlO, D. S. C.; AROEIRA, L. J. M.; ALVIM, M. J.; CARVALHO, M. M. Características produtivas e qualitativas de pastagem de braquiária em monocultivo e consorciada com estilosantes. Pesquisa Agropecuária Brasileira, Brasília, v. 38, n. 3, p. 421-426, 2003.

PACIULLO, D. S. C.; DERESZ, F.; LOPES, F. C. F.; AROEIRA, L. J. M.; MORENZ, M. J. F.; VERNEQUE, R. S. Disponibilidade de matéria seca, composição química e consumo de forragem em pastagem de capimelefante nas estações do ano. Arquivo Brasileiro de Medicina Veterinária e Zootecnia, Belo Horizonte, v. 60, n. 4, p. 904-910, 2008.

PARIS, W.; CECATO, U.; BRANCO, A. F.; BARBERO, L. M.; GALBEIRO, S. Produção de novilhas de corte em pastagem de Coastcross-1 consorciada com Arachis pintoi com e sem adubação nitrogenada. Revista Brasileira de Zootecnia, Viçosa, MG, v. 38, n. 1, p. 122129, 2009.

PATÊS, N. M. S.; PIRES, A. J. V.; CARVALHO, G. G. P.; OLIVEIRA, A. C.; FONCÊCA, M. P. F.; VELOSO, C. M. Produção e valor nutritivo do capim-Tanzânia fertilizado com nitrogênio e fósforo. Revista Brasileira de Zootecnia, Viçosa, MG, v. 37, n. 11, p. 1934-1939, 2008.
PIZARRO, E. A. Novel grasses and legumes germplasm: advances and perspectives for tropical zones. In: INTERNATIONAL GRASSLAND CONGRESS, 19., 2001, Piracicaba. Proceedings... Piracicaba, 2001. CDROM.

PRIMAVESI, O.; CORRÊA, L. A.; PRIMAVESI, A. C.; CANTARELLA, H.; ARMELIN, M. J. A.; SILVA, A. G.; FREITAS, A. R. Adubação com uréia em pastagem de Cynodon dactylon cv. Coastcross sob manejo rotacionado: eficiência e perdas. São Carlos: Embrapa Pecuária Sudeste, 2001. 42 p. (Embrapa Pecuária Sudeste. Circular técnica, 30).

RIBEIRO JÚNIOR, J. Análises estatísticas no SAEG: sistema de análises estatísticas e genéticas. Versão 8.1. Viçosa: UFV, 2001. 301 p.

TILLEY, J. M. A.; TERRY, R. A. A two-stage technique for in vitro digestion of forage crop. Journal of the British Grassland Society, Hurley, v. 18, n. 2, p. 104-111, feb. 1963.

VAN SOEST, P. J. Nutritional ecology of the ruminant. 2. ed. Ithaca: Cornell Univ. Press, 1994. 476 p.

VAN SOEST, P. J.; ROBERTSON, J. B.; LEWIS, B. A. Methods for dietary fiber, and nonstarch polysaccharides in relation to animal nutrition. Journal of Dairy Science, Madison, v. 74, n. 10, p. 3583-3597, 1991.

WERNER, J. C.; PAULINO, V. T.; CANTARELLA, H.; ANDRADE, N. O.; QUAGGIO, J. A. Forrageiras. In: RAIJ, B. van; CANTARELLA, H.; QUAGGIO, J. A.; FURLANI, A. M. C. (Ed.). Recomendações de adubação e calagem para o Estado de São Paulo. Campinas: Instituto Agronômico, 1996. p. 263-273. (IAC. Boletim técnico, 100). 